\title{
Evaluation of microsatellite instability in women with epithelial ovarian cancer
}

\author{
LEONARDO PANDOLFI CALIMAN $^{1}$, RUBENS LENE CARVALHO TAVARES ${ }^{1}$, JOSIANE BARBOSA PIEDADE ${ }^{2}$, \\ ANA CAROLINA SILVANO COUTO DE ASSIS ${ }^{2}$, KAREN DE JESUS DIAS DA CUNHA ${ }^{2}$, \\ LETÍCIA DA CONCEIÇÃO BRAGA ${ }^{2}$, LUCIANA MARIA SILVA ${ }^{2}$ and AGNALDO LOPES DA SILVA FILHO ${ }^{1}$ \\ ${ }^{1}$ Department of Obstetrics and Gynecology, Faculty of Medicine, Federal University of Minas Gerais (UFMG), 30130-100; \\ ${ }^{2}$ Research and Development Center, Ezequiel Dias Foundation, 30510-010, Belo Horizonte, Minas Gerais, Brazil
}

Received March 9, 2012; Accepted June 18, 2012

DOI: $10.3892 / \mathrm{ol} .2012 .776$

\begin{abstract}
The function of microsatellite instability (MSI) and the optimal panel of markers for epithelial ovarian cancer (EOC) are not well established. This study aimed to use the National Cancer Institute (NCI) markers BAT25, BAT26, D2S123, D5S346 and D17S250 to evaluate MSI in patients with ovarian serous cystadenocarcinoma, compared with ovarian serous cystadenoma and normal ovaries. A total of 37 patients were divided into three groups, as follows: cystadenocarcinoma $(n=13)$, cystadenoma $(n=10)$ and normal ovaries $(n=14)$. DNA was extracted with TRIzol and quantified by spectrophotometry. MSI was evaluated by polymerase chain reaction (PCR), and classified as high (MSI-H), low (MSI-L) or stable (MSS). FIGO staging was I/II in $23.1 \%$ and III/IV in $76.9 \%$ of the cystadenocarcinoma group. Polymorphisms were found using at least one marker in 32 women, and were observed with D2S123 (83.7\%), D17S250 (81.1\%), D5S346 (72.9\%), BAT25 (21.6\%) and BAT26 (16.2\%) markers. In the cystadenocarcinoma group, BAT25, BAT26, D2S123, D5S346 and D17S250 markers were positive in 30.8, 76.9, 53.8, 69.2 and $69.2 \%$ of patients, respectively. The same markers were positive in $30,50,40,60$ and $30 \%$ of the cystadenoma group, and $50,71.4,71.4,64.3$ and $63.3 \%$ in the normal ovary group, respectively. MSI-H was present in $84.6,60$ and $78.6 \%$ of the cystadenocarcinoma, cystadenoma and normal patients, respectively. MSI-L was detected in 0,30 and 7.1\%, and MSS was identified in 15.4, 10 and $14.3 \%$ of the cystadenocarcinoma, cystadenoma and normal patients, respectively. The frequency of MSI in both benign epithelial ovarian neoplasms and in normal ovaries was high, as well as in EOC, with no statistically significant difference between the groups. This
\end{abstract}

Correspondence to: Dr Rubens Lene Carvalho Tavares, Department of Obstetrics and Gynecology, Faculty of Medicine, Federal University of Minas Gerais (UFMG), Alfredo Balena 190, Santa Efigênia, 30130-100, Belo Horizonte, Minas Gerais, Brazil

E-mail: tavaresr@medicina.ufmg.br

Key words: microsatellite instability, ovarian cancer, National Cancer Institute markers suggests that MSI may arise as a consequence of the ovulatory process, and not solely as a feature of malignant ovarian tumors.

\section{Introduction}

Epithelial ovarian cancer (EOC) has a high mortality rate (1); it is the leading cause of death among gynecological tumors, and the fourth leading cause of cancer-related mortality among women in the United States (2). Due its nonspecific symptoms and lack of effective screening methods (3), approximately two-thirds of cases are diagnosed in stages III and IV, with a five-year survival rate of $10-20 \%(4,5)$. Approximately $90 \%$ of ovarian tumors originate from epithelial cells $(6,7)$. The mortality rate has not changed in the last two decades (8).

A group of enzymes known as the DNA mismatch repair (MMR) system is responsible for repairing mutations. Hereditary nonpolyposis colorectal cancer (HNPCC) is the third leading cause of hereditary ovarian cancer, and is caused by mutations in genes of the MMR system. One of the consequences of deficient MMR is microsatellite instability (9), which carries somatic mutations in tumor suppressor genes, oncogenes, apoptosis and detoxification genes, and is involved in both the initiation and progression of tumors (10).

HNPCC has been studied using a panel of five National Cancer Institute (NCI) markers, which includes two mononucleotides (BAT25 and BAT26) and three dinucleotides (D2S123, D5S346 and D17S250) (11). MSI is identified when the alleles detected in the microsatellite DNA of tumor samples are not present in normal tissue samples from the same individual (12). It is also believed that genetic changes may occur in response to constant ovulation $(13,14)$.

The identification of MMR system mutations by microsatellite instability (MSI) in women with EOC may help us to understand tumor biology and its pathogenesis $(11,15,16)$. Despite the evidence of the involvement of the MMR system in the complex process of ovarian carcinogenesis, the actual function of MSI and the optimal panel of markers for EOC are not well established $(9,17)$. This study uses the NCI markers with the aim of evaluating the expression of MSI in patients with ovarian serous cystadenocarcinoma, compared with ovarian serous cystadenoma and normal ovaries. 
Table I. Description of National Cancer Institute primers for PCR.

\begin{tabular}{|c|c|c|c|}
\hline Markers & Primers & $\mathrm{AT}\left({ }^{\circ} \mathrm{C}\right)$ & Product size (bp) \\
\hline \multirow[t]{2}{*}{ BAT25 } & Forward: TCG CCT CCA AGA ATG TAA GT & & \\
\hline & Reverse: TCT GGA TTT TAA CTA TGG CTC & 56 & $110-130$ \\
\hline \multirow[t]{2}{*}{ BAT26 } & Forward: TGA CTA CTT TTG ACT TCA GCC & & \\
\hline & Reverse: AAC CAT TCA ACA TTT TTA ACC C & 56 & $100-120$ \\
\hline \multirow[t]{2}{*}{$\mathrm{D} 2 \mathrm{~S} 123$} & Forward: AAA CAG GAT GCC TGC CTT TA & & \\
\hline & Reverse: GGA CTT TCC ACC TAT GGG AC & 55 & $200-230$ \\
\hline \multirow[t]{2}{*}{ D5S346 } & Forward: AGC AGA TAA GAC AGT ATT ACT AGT T & & \\
\hline & Reverse: ACT CAC TCT AGT GAT AAA TCG GG & 55 & $100-130$ \\
\hline \multirow[t]{2}{*}{$\mathrm{D} 17 \mathrm{~S} 250$} & Forward: GGA AGA ATC AAA TAG ACA AT & & \\
\hline & Reverse: GCT GGC CAT ATA TAT ATT TAA ACC & 52 & $140-170$ \\
\hline
\end{tabular}

AT, annealing temperature.

\section{Materials and methods}

Patients. A total of 37 patients were prospectively evaluated in three different groups, as follows: ovarian serous cystadenocarcinoma $(n=13)$, ovarian serous cystadenoma $(n=10)$ and normal ovaries ( $n=14)$, from February 2008 to July 2010. The study was approved by the ethics committee of UNA University Center (protocol 0005.0.391.000-10) and all patients signed informed consent forms.

All patients underwent clinical and gynecological examination and transvaginal ultrasound, prior to the study. Surgical staging was performed in patients with ovarian serous cystadenocarcinoma, according to the International Federation of Gynecology and Obstetrics (FIGO). Normal ovarian tissue was obtained from patients undergoing oophorectomy, during total abdominal hysterectomy for treatment of benign gynecological disease. Histological evaluation was performed by a pathologist. None of the patients had received prior treatment with chemotherapy and/or radiotherapy, or acute infectious peritoneal process.

Polymorphisms and microsatellite instability. Peripheral blood samples were collected prior to the induction of anesthesia in tubes containing EDTA (Becton Dickinson, Franklin Lakes, NJ, USA). Ovarian tissue samples were collected intraoperatively from the solid portion of the tumor without necrosis, and immediately frozen in liquid nitrogen. DNA was extracted with $1 \mathrm{~m} 1 \mathrm{TRIzol}^{\circledR}$ reagent (Invitrogen, Carlsbad, CA, USA), using 50-100 mg frozen ovarian tissue or $500 \mu \mathrm{l}$ blood. The gDNA was quantified using the NanoVue spectrophotometer Pathlength Fluid Calibration kit (GE Healthcare, Little Chalfont, Buckinghamshire, UK) at wavelengths of 260 and $280 \mathrm{~nm}$.

The MSI was evaluated using the primers described in Table I, in two different PCR reactions (blood and ovarian tissue). We used GoTaq ${ }^{\circledR}$-Green Master mix 1X (Promega, Sao Paulo, SP, Brazil), $1 \mu \mathrm{M}$ of each primer, and $10 \mathrm{ng}$ DNA from each sample. Tubes were incubated at $95^{\circ} \mathrm{C}$ for 2 min to denature the sample. Cycles of PCR amplification were performed as follows: denaturation at $94^{\circ} \mathrm{C}$ for $30 \mathrm{sec}$, annealing at 52,
55 or $56^{\circ} \mathrm{C}$ for $45 \mathrm{sec}$, extension at $72^{\circ} \mathrm{C}$ for $30 \mathrm{sec}$, and a final extension at $72^{\circ} \mathrm{C}$ for $5 \mathrm{~min}$ (Table I). A $15-\mu 1$ sample of the PCR products was analyzed by $7.5 \%$ polyacrylamide gel electrophoresis at 100 volts. The gels were then incubated in freshly prepared silver nitrate solution $(0.2 \%)$. PCR was performed with negative and positive controls.

The identification of polymorphisms and analysis of genomic instability were performed by comparing amplified alleles in samples of ovarian tissue and peripheral blood. Presence of MSI was confirmed when monomorphic or polymorphic variants identified in microsatellite DNA in ovarian tissue samples were not present in the peripheral blood sample from the same individual. The level of MSI was classified as high (MSI-H) when two or more of the markers tested demonstrated instability, low (MSI-L) when one of the markers tested demonstrated instability, or stable (MSS) when no instability was detected. All analyses were reviewed by two authors independently.

Real-time PCR. cDNA was generated from $2 \mathrm{mg}$ total RNA using Illustra Ready-to-Go RT-PCR beads (GE Healthcare) in a total volume of $50 \mu \mathrm{l}$, according to the manufacturer's instructions. PCR primers were used as described in previous publications: $M L H 1$ : forward, 5'-CTGAAGGCACTTCCGTT GAG-3' and reverse, 5'-TGGCCGCTGGATAACTTC-3'; MSH2: forward, 5'-GAGGCTCTCCTCATCCAGATTG-3' and reverse, 5'-GGCCTGGAATCTCCTCTATCAC-3'; TATA: forward, 5'-TGCACAGGAGCCAAGAGTGAA-3' and reverse, 5'-CACATCACAGCTCCCCACCA-3' (18). qRT-PCR was performed using $10 \mu \mathrm{l}$ duplicate reactions with $1 \mathrm{X}$ Brilliant II SYBR $^{\circledR}$-Green qPCR Master mix (Agilent Technologies, La Jolla, CA, USA), 0.2 $\mu$ 1 Rox (1:500), 0.25-0.30 $\mu \mathrm{M}$ of the primers, and $40 \mathrm{ng} / \mu \mathrm{l} \mathrm{cDNA}$ (RNA equivalent) for each experiment. The Agilent MX 3005P detection system (Stratagene) was used. The reference loci TATA binding protein (TBP) was used as the normalization gene. PCR amplification was performed as follows: $95^{\circ} \mathrm{C}$ for $10 \mathrm{~min} ; 40$ cycles of $95^{\circ} \mathrm{C}$ for $30 \mathrm{sec}$, annealing at $60^{\circ} \mathrm{C}$ for $60 \mathrm{sec}$ and extension at $72^{\circ} \mathrm{C}$ for $60 \mathrm{sec}$. The optimization of the RT-qPCR reaction was performed according to the manufacturer's instructions. No 
Table II. Comparison between serous cystadenocarcinoma, serous cystadenoma and normal ovary.

\begin{tabular}{lccc}
\hline Variable $^{\mathrm{a}}$ & Cystadenocarcinoma & Cystadenoma & Normal ovary \\
\hline Number of patients & 13 & 10 & 14 \\
Age, years (mean \pm SD) & $58.8 \pm 12.2$ & $52.3 \pm 16.4$ & $51.2 \pm 8.7$ \\
Menopause, $\mathrm{n}$ & 10 & 5 & 14 \\
Parity, mean \pm SD & $2.23 \pm 1.87$ & $2.2 \pm 2.86$ & $2.14 \pm 1.91$ \\
NCI markers, n (\%) & & & 0.013 \\
BAT25 & $4(30.8)$ & $3(30)$ & 0.994 \\
BAT26 & $10(76.9)$ & $5(50)$ & $10(71.4)$ \\
D2S123 & $7(53.8)$ & $4(40)$ & $10(71.4)$ \\
D5S346 & $9(69.2)$ & $6(60)$ & $9(64.3)$ \\
D17S250 & $9(69.2)$ & $3(30)$ & $9(64.3)$ \\
\hline
\end{tabular}

${ }^{a}$ One-way ANOVA and Newman-Keuls post-hoc tests were used for age and parity. Chi-square test was used for menopause. Chi-square test for independence were used for NCI markers.

template controls were included in the assay for any gene. A melting curve was constructed for each primer pair to confirm the product specificity.

Statistical analysis was performed with SPSS 18.0 (SPSS Inc., Chicago, IL, USA). The Chi-square and Fisher's exact tests were used to establish the differences between the groups. Gene expression levels from qPCR were compared using the Kruskal-Wallis test. $\mathrm{P}<0.05$ was considered to indicate a statistically significant result.

\section{Results}

The FIGO stage was I/II in three patients (23.1\%) and III/IV in 10 patients $(76.9 \%)$ in the serous cystadenocarcinoma group. There were no differences between the groups regarding age $(\mathrm{P}=0.254)$ or parity $(\mathrm{P}=0.994)$, but there was a difference with regard to menopausal status $(\mathrm{P}=0.013$; Table II).

Polymorphisms were found using at least one marker in 32 women (86.4\%), and were observed with D2S123 (83.7\%), D17S250 (81.1\%), D5S346 (72.9\%), BAT25 (21.6\%) and BAT26 (16.2\%) markers. Polymorphisms were similar between MSS samples for D2S123, while the polymorphism observed for D5S346 differed between the MSI samples of ovarian tissue and peripheral blood. Fig. 1 shows the results of MSI analysis in patients with cystadenocarcinoma, cystadenoma and normal ovaries, respectively.

MSI was identified in 25 cases (67.6\%) with BAT26, 24 cases $(64.9 \%)$ with D5S346, 21 cases $(56.8 \%)$ with D2S123 and D17S250, and 14 cases (37.8\%) with BAT25. In the cystadenocarcinoma group, BAT25, BAT26, D2S123, D5S346 and D17S250 markers were positive in 30.8, 76.9, 53.8, 69.2 and $69.2 \%$ of patients, respectively. The same markers were positive for $30,50,40,60$ and $30 \%$ in the cystadenoma group, and $50,71.4,71.4,64.3$ and $63.3 \%$ of the normal ovary group, respectively. There were no differences between the specific NCI markers among the three studied groups (Fig. 2, Table II).

MSI-H was present in $84.6,60$ and $78.6 \%$ of the cystadenocarcinoma, cystadenoma and normal patients, respectively. Although there was a lower incidence of MSI-H in the cystad-

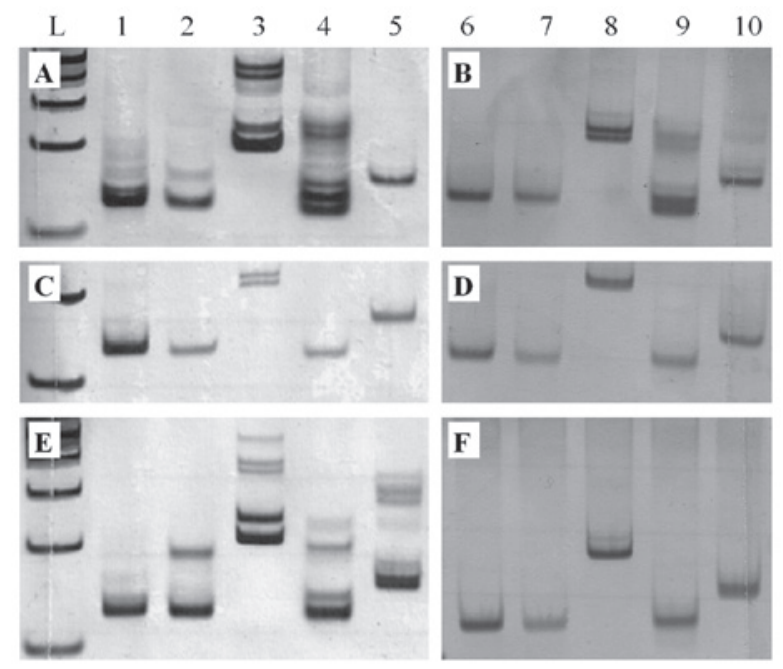

Figure 1. Polyacrylamide gel electrophoresis (7.5\%) of NCI markers (A, C, E) and peripheral blood samples $(\mathrm{B}, \mathrm{D}, \mathrm{F})$ of patients. (A, B) Cystadenocarcinoma, (C, D) cystadenoma, and (E, F) normal ovarian tissue. Columns 1 and 6 , BAT25; 2 and 7, BAT26; 3 and 8, D2S123; 4 and 9, D5S346; and 5 and 10, D17S250. BAT25, BAT26, D2S123 (A), D2S123 (C) and BAT26, D2S123, D5S346, D17S250 (E) polymorphic alleles are present in the ovarian tissues and absent in the peripheral blood samples (B, D, F), characterized as MSI-H, MSI-L and MSI-H, respectively. L, 100-bp DNA ladder.

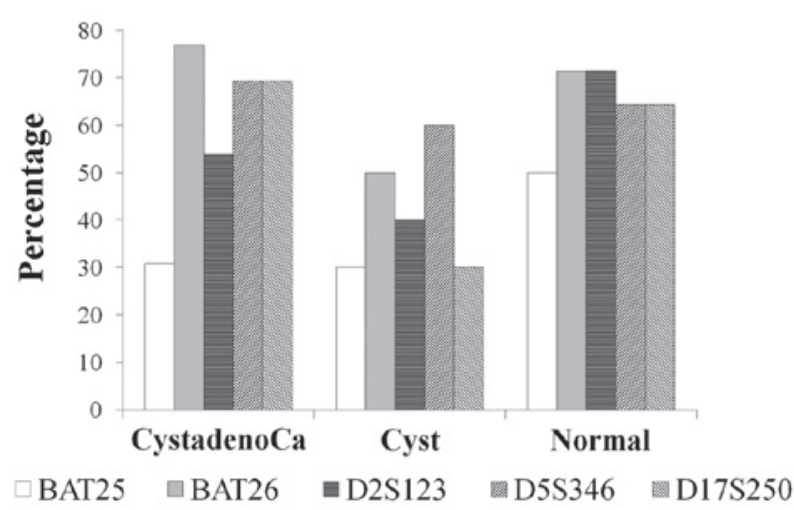

Figure 2. NCI marker frequency in cystadenocarcinoma (CystadenoCa), cystadenoma (Cyst) and normal ovaries. 


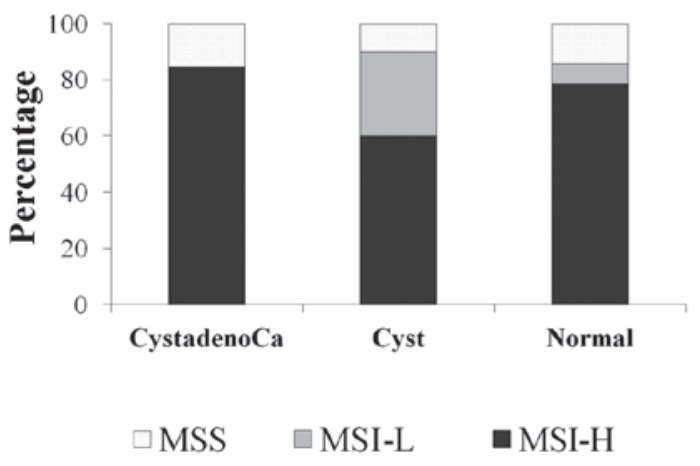

Figure 3. Frequency of microsatellite instability (MSI). High (MSI-H), low (MSI-L) or stable (MSS).
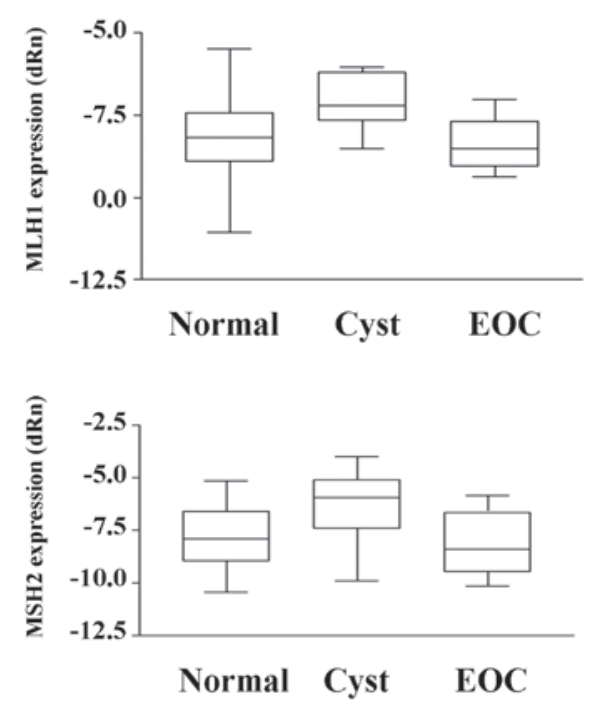

Figure 4. qPCR for $M L H 1$ and $M S H 2$ genes in the normal ovary, cystadenoma (Cyst) and cystadenocarcinoma (EOC) groups. There was no difference in gene expression levels between groups, when compared by the Kruskal-Wallis test.

enoma group, the difference was not statistically significant. MSI-L was detected in 0,30 and 7.1\%, and MSS was identified in $15.4,10$ and $14.3 \%$ of the cystadenocarcinoma, cystadenoma and normal patients, respectively (Fig. 3).

MLH1 and MSH2 gene expression by qPCR revealed no statistically significant difference among the three studied groups ( $\mathrm{P}=0.089$ and $\mathrm{P}=0.122$, respectively; Fig. 4).

\section{Discussion}

Despite advances in EOC therapy, mortality and morbidity have not changed in recent decades (8). The MMR system is a well-defined molecular pathway of carcinogenesis in hereditary and sporadic tumors (9).

Several techniques have been used to evaluate the MMR system, and, in the present study, we assessed MMR deficiencies through the analysis of MSI in patients with EOC compared with benign and normal ovarian tissue, which is a technique frequently used by other researchers. A variety of markers used to identify MSI in EOC have been described in the literature, but the optimal markers are not yet well defined.

In our study, MSI was observed in $84.6 \%$ of serous cystadenocarcinoma patients, and all of them had MSI-H. In 2001, Sood et al were the first to use the NCI markers to determine MSI in patients with EOC (11). These authors reported an MSI frequency of $19 \%$, of which $11 \%$ had MSI-H, and $8 \%$ had MSI-L. In 2006, Lu et al used the same NCI markers and identified MSI in 53\% of patients, of which $20 \%$ had MSI-H (19). In 2008, Yoon et al reported an MSI frequency of $8 \%$, of which $4 \%$ had MSI-H (20). The sample size may explain the differences found in the frequency of MSI between the present study and those in the literature. The highest frequency of MSI was found with the BAT26 marker $(67.6 \%)$ followed by the D5S346 marker (64.9\%). Sood et al reported that BAT25 was the most frequent (11\%), followed by D5S346 (10\%).

An important feature taken into account in the study of Sood et al was the polymorphic variation in the amplification of alleles of NCI markers. Polymorphism identification can prevent a polymorphic marker from being characterized as unstable, which would undermine the results. In the present study, polymorphism was also considered for the determination of MSI. Among the 37 women studied, 32 (86.4\%) revealed polymorphism in the microsatellite analysis. The highest frequency of polymorphism was observed in the D2S123 (83\%) and D17S250 markers (81\%).

To assist in the identification of polymorphisms and MSI we compared DNA leukocytes with the DNA of ovarian tissue. The present study used peripheral blood samples, similar to Sood et al in 2001, while in 2008 Yoon et al utilized samples from paraffinized gynecological tissue for normal DNA extraction $(11,20)$.

Data in the literature suggests that women with malignant ovarian tumors associated with a deficiency of the MMR system have a higher survival rate, possibly related to less aggressive tumor behavior $(21,22)$. In addition, MMR deficiency may be a predictor of tumor resistance to chemotherapy $(15,23)$. However, a systematic review involving 22 studies found that the association between clinical and/or epidemiological factors with MSI or MMR system deficiencies in EOC has not been adequately studied (24). In this study, there was no statistically significant association of MSI with clinical data in the different comparison groups. The menopausal status was the only statistically significant difference between groups, but this factor was not associated with MSI $(\mathrm{P}=0.542)$.

In the present study, MSI of EOC was compared with cystadenoma and normal ovarian tissue. To the best of our knowledge, no other studies have used identical comparison groups. The frequency of MSI in both benign epithelial ovarian neoplasms and normal ovaries was high, as well as in EOC, with no statistically significant difference between groups. This suggests that MSI may arise as a consequence of the ovulatory process, and not solely as a feature of malignant ovarian tumor development. Repeated injuries in ovarian epithelium, due to an incessant ovulatory process, would result in genetic alterations that compromise the MMR system, culminating in MSI.

Additionally, to better assess the DNA mismatch repair system, we studied $M L H 1$ and $M S H 2$ gene expression using qPCR. Our results did not demonstrate any difference between 
groups when comparing normal, cystadenoma and cystadenocarcinoma samples.

Ovulation requires intense cell replication to repair and restore epithelial ovarian microtrauma and may induce permanent genetic changes that accumulate in cellular DNA, causing a malfunction of the cell, which predisposes it to epithelial ovarian mutagenesis $(13,14)$. The presence of MSI as a consequence of the ovulatory process reinforces the importance of certain clinical risk factors, including early menarche, late menopause and infertility, while factors that decrease the number of ovulatory cycles, such as pregnancy, lactation and contraceptive use, reduce the risk of ovarian cancer throughout life (25).

The results revealed a high frequency of MSI in normal ovarian tissue, benign and malignant tumors of the ovary, with no difference in the expression of the MMR system genes, suggesting that MSI may be inherent to the ovulatory process. In conclusion, MSI does not appear to play a role in ovarian carcinogenesis.

\section{References}

1. Silva-Filho AL, Carmo GA, Athayde GR, Assis ME, Almeida RC Leal RH, Lamaita RM, Santos-Júnior JL and Castro e Silva JG: Safe fertility-preserving management in gynecological malignancies. Arch Gynecol Obstet 275: 321-330, 2007.

2. Jemal A, Siegel R, Ward E, Hao Y, Xu J and Thun MJ: Cancer statistics, 2009. CA Cancer J Clin 59: 225-249, 2009.

3. Dorigo O and Berek JS: Personalizing CA125 levels for ovarian cancer screening. Cancer Prev Res (Phila) 4: 1356-1359, 2011.

4. Brewer MA, Johnson K, Follen M, Gershenson D and Bast R Jr: Prevention of ovarian cancer: intraepithelial neoplasia. Clin Cancer Res 9: 20-30, 2003.

5. Roett MA and Evans P: Ovarian cancer: an overview. Am Fam Physician 80: 609-616, 2009.

6. Feeley KM and Wells M: Precursor lesions of ovarian epithelial malignancy. Histopathology 38: 87-95, 2001.

7. Dubeau L: The cell of origin of ovarian epithelial tumours. Lancet Oncol 9: 1191-1197, 2008.

8. Berek JS, Chalas E, Edelson M, Moore DH, Burke WM, Cliby WA, Berchuck A; Society of Gynecologic Oncologists Clinical Practice Committee: Prophylactic and risk-reducing bilateral salpingo-oophorectomy: recommendations based on risk of ovarian cancer. Obstet Gynecol 116: 733-743, 2010.

9. Pal T, Permuth-Wey J and Sellers TA: A review of the clinical relevance of mismatch-repair deficiency in ovarian cancer. Cancer 113: 733-742, 2008.

10. Sidransky D: Emerging molecular markers of cancer. Nat Rev Cancer 2: 210-219, 2002
11. Sood AK, Holmes R, Hendrix MJ and Buller RE: Application of the National Cancer Institute international criteria for determination of microsatellite instability in ovarian cancer. Cancer Res 61: 4371-4374, 2001

12. Singer G, Kallinowski T, Hartmann A, Dietmaier W, Wild PJ, Schraml P, Sauter G, Mihatsch MJ and Moch H: Different types of microsatellite instability in ovarian carcinoma. Int J Cancer 112: 643-646, 2004

13. Fathalla MF: Incessant ovulation-a factor in ovarian neoplasia? Lancet 2: 163, 1971

14. Hennessy BT, Coleman RL and Markman M: Ovarian cancer. Lancet 374: 1371-1382, 2009.

15. Massey A, Offman J, Macpherson P and Karran P: DNA mismatch repair and acquired cisplatin resistance in E. coli and human ovarian carcinoma cells. DNA Repair (Amst) 2: 73-89, 2003.

16. Crijnen TE, Janssen-Heijnen ML, Gelderblom H, Morreau J, Nooij MA, Kenter GG and Vasen HF: Survival of patients with ovarian cancer due to a mismatch repair defect. Fam Cancer 4: 301-305, 2005.

17. Lawes DA, SenGupta S and Boulos PB: The clinical importance and prognostic implications of microsatellite instability in sporadic cancer. Eur J Surg Oncol 29: 201-212, 2003.

18. Vaughn CP, Lyon E and Samowitz WZ: Confirmation of single exon deletions in MLH1 and MSH2 using quantitative polymerase chain reaction. J Mol Diagn 10: 355-360, 2008.

19. Lu Y, Liu XS, Wang YX, Song HY and Zhong N: Study of microsatellite instability in epithelial ovarian tumors. Beijing Da Xue Xue Bao 38: 62-65, 2006.

20. Yoon BS, Kim YT, Kim JH, Kim SW, Nam EJ, Cho NH, Kim JW and Kim S: Clinical significance of microsatellite instability in sporadic epithelial ovarian tumors. Yonsei Med J 49: 272-278, 2008.

21. Gryfe R, Kim H, Hsieh ET, Aronson MD, Holowaty EJ, Bull SB, Redston $\mathrm{M}$ and Gallinger S: Tumor microsatellite instability and clinical outcome in young patients with colorectal cancer. N Engl J Med 342: 69-77, 2000

22. Ribic CM, Sargent DJ, Moore MJ, Thibodeau SN, French AJ, Goldberg RM, Hamilton SR, Laurent-Puig P, Gryfe R, Shepherd LE, Tu D, Redston M and Gallinger S: Tumor microsatellite-instability status as a predictor of benefit from fluorouracil-based adjuvant chemotherapy for colon cancer. N Engl J Med 349: 247-257, 2003.

23. Sakamoto-Hojo ET and Balajee AS: Targeting poly (ADP) ribose polymerase I (PARP-1) and PARP-1 interacting proteins for cancer treatment. Anticancer Agents Med Chem 8: 402-416, 2008.

24. Murphy MA and Wentzensen N: Frequency of mismatch repair deficiency in ovarian cancer: a systematic review. International Journal of Cancer 129: 1914-1922, 2011.

25. Guppy AE, Nathan PD and Rustin GJ: Epithelial ovarian cancer: a review of current management. Clin Oncol (R Coll Radiol) 17: $399-411,2005$. 